IZA DP No. 4681

Incentive Effects of Unemployment Insurance

Savings Accounts: Evidence from Chile

Gonzalo Reyes Hartley

Jan C. van Ours

Milan Vodopivec

January 2010 


\title{
Incentive Effects of Unemployment Insurance Savings Accounts: Evidence from Chile
}

\author{
Gonzalo Reyes Hartley \\ Superintendencia de Pensiones, Santiago, Chile \\ Jan C. van Ours \\ CentER, Tilburg University, \\ University of Melbourne, CEPR, CESifo and IZA \\ Milan Vodopivec \\ World Bank and IZA
}
Discussion Paper No. 4681
January 2010

IZA

P.O. Box 7240

53072 Bonn

Germany

Phone: +49-228-3894-0

Fax: +49-228-3894-180

E-mail: iza@iza.org

\begin{abstract}
Any opinions expressed here are those of the author(s) and not those of IZA. Research published in this series may include views on policy, but the institute itself takes no institutional policy positions.

The Institute for the Study of Labor (IZA) in Bonn is a local and virtual international research center and a place of communication between science, politics and business. IZA is an independent nonprofit organization supported by Deutsche Post Foundation. The center is associated with the University of Bonn and offers a stimulating research environment through its international network, workshops and conferences, data service, project support, research visits and doctoral program. IZA engages in (i) original and internationally competitive research in all fields of labor economics, (ii) development of policy concepts, and (iii) dissemination of research results and concepts to the interested public.
\end{abstract}

IZA Discussion Papers often represent preliminary work and are circulated to encourage discussion. Citation of such a paper should account for its provisional character. A revised version may be available directly from the author. 


\section{ABSTRACT \\ Incentive Effects of Unemployment Insurance Savings Accounts: Evidence from Chile*}

This study examines the determinants of job-finding rates of unemployment benefit recipients under the Chilean program. This is a unique, innovative program that combines social insurance through a solidarity fund (SF) with self-insurance in the form of unemployment insurance savings accounts (UISAs) - so as to mitigate the moral hazard problem of traditional unemployment insurance programs. Our study is the first one to empirically investigate whether UISAs improve work incentives. We find that for beneficiaries using the $\mathrm{SF}$, the pattern of job finding rates over the duration of unemployment is consistent with moral hazard effects, while for beneficiaries relying on UISAs, the pattern is free of such effects. We also find that for benefit recipient not entitled to use the SF, the amount of accumulation on the UISA does not affect the exit rate from unemployment, suggesting that such individuals internalize the costs of unemployment benefits. Our results provide strong support to the idea that UISAs can improve work incentives.

JEL Classification: C41, H55, J64, J65

Keywords: unemployment insurance, unemployment duration, savings accounts

Corresponding author:

Jan C. van Ours

CentER

Tilburg University

P.O. Box 90153

5000 LE Tilburg

The Netherlands

E-mail: vanours@uvt.nl

\footnotetext{
* This paper was made possible by a Cooperation Agreement between Superintendencia de Pensiones of Chile and the World Bank. Helpful comments from participants of a seminar at Pablo de Olavide University (Seville), a CEPR workshop at Bocconi University (Milano), and an IZA workshop (Bonn), as well as comments from Tito Boeri, Eduado Fajnzylber and Pamela Gana are gratefully acknowledged; excellent research assistance was provided by Evelyn Benvin and Lenny Stoeldraijer.
} 


\section{Introduction}

Unemployment insurance (UI) offers financial compensation to qualifying workers for income loss due to unemployment. By providing protection against unemployment risk, the program seeks to bring welfare gains: it increases the sense of security among employed workers and, thanks to its large coverage and wide-base pooling of risk, it typically enables strong smoothening of consumption patterns. For example, studies on the U.S. find that the welfare of benefit recipient households is on average only 3 to 8 percent lower than the welfare of otherwise identical households (Hamermesh and Sleznick,1995), and that in the absence of unemployment insurance, average consumption expenditures would fall by about 20 percent (Gruber, 1997).

While UI programs provide protection against the hardship of job loss, the evidence shows that such protection is typically produced at a cost of increased work disincentives and wage pressures, and, consequently, of increased unemployment. The problem of moral hazard in UI programs has been extensively studied and documented (see reviews of Holmlund 1998 and Vodopivec 2004). Spurred by adverse incentives created by UI programs, policymakers have often redesigned such programs, trying to reduce the moral hazard and striking a balance between the protection and disincentive effects.

There are several mechanisms that help reduce work disincentives in UI benefit programs: monitoring and benefit sanctions, work requirements, and financial incentives. ${ }^{1}$ First, recipients can be subject to monitoring of their job-search activities and labor market status, and if they do not meet certain performance criteria, they can be exposed to sanctions (such as benefit reductions). Second, work or other requirements can be imposed on benefit recipients, forcing them to participate in public works or training, for example, in order to retain benefits. And third, financial incentives can be introduced to make reemployment more attractive. Options include reducing benefit levels over time, introducing bonuses for speedy reemployment, lowering income tax rates or introducing employment subsidies (such as earned income tax credit), and unemployment insurance savings accounts (UISAs).

Among new approaches used to reduce work disincentives, UISAs are among the most

\footnotetext{
${ }^{1}$ compare Fredriksson and Holmlund (2006a, 2006b). For evaluation of various mechanisms that help reduce work disincentives in UI programs, see overviews, for example, in Abbring et al. (2005), Lalive et al. (2006) and Van Ours and Vodopivec (2006).
} 
radical and perhaps promising ones. Under the UISA system, each worker is required to save a fraction of earnings in his or her account, and draw unemployment benefits from it. By internalizing the costs of unemployment benefits, the UISA system is expected to reinforce worker incentives and thus to avoid or reduce the moral hazard inherent in traditional UI programs while, under some variants of the program, providing the same protection as the traditional UI system. The system is thus credited with a potential to substantially decrease overall unemployment and, by lowering payroll taxes, increase wages.

In contrast to the other mechanisms used to address work disincentives in UI programs (or other cash benefit systems), studies on UISAs are rare and mostly limited to theoretical contributions. In particular, so far there have been no empirical evidence whether UISAs can reduce moral hazard problems plaguing traditional UI schemes, mainly because only a few countries in Latin America and Austria have introduced such a system, and non-availability of experimental approaches and heavy informational requirements have prevented such studies (for an overview of existing UISAs in Latin America, see Ferrer and Riddell, 2009). Taking advantage of the recently introduced, innovative Chilean unemployment benefit system, this paper is the first attempt to test empirically the theoretical prediction that UISAs reduce the moral hazard problems inherent in traditional UI schemes.

In 2002, Chile introduced a new UI program which combines social insurance with self-insurance. Unemployment contributions, paid by both workers and employers, are split between individual-level UISAs and a common, solidarity fund (SF), the latter being cofinanced by the government. To stimulate reemployment, benefit recipients first draw resources from their UISAs and, upon depletion, from the solidarity fund (to reach target replacement rates, solidarity funding may top resources drawn from UISAs also during initial withdrawals). Withdrawals from individual accounts are triggered by separation from the employer, regardless of the reason. Withdrawals from the common fund are triggered by insufficient resources on individual accounts, if the claimant satisfies the usual conditions of continuing eligibility under UI. Only those who prior to unemployment worked under permanent contracts and were laid off for reasons attributable to the employer can access solidarity funding, but even if they qualify, workers may opt not to choose the option of using SF (presumably, if they want to avoid additional conditions for continuing benefit eligibility imposed under SF option, see below). In August 2008, the program had 2.9 million active contributors, representing 77 percent of private sector wage and salary 
workers the target population, and distributed benefits to 105,000 members, approximately to one per every four of unemployed workers.

A natural, so far unanswered question thus arises: is the Chilean system by partly relying on savings accumulated on UISAs an effective tool to combat the moral hazard plaguing the traditional UI programs? That is, by drawing on UISAs (in a particular combination with solidarity funding), does the program improve job search incentives and/or reduce reservation wages, and thus increase the exit rate from insured unemployment as theoretical models predict? After all, individuals may be myopic and may discount heavily resources the access to which can only be gained after a long time, often a decade or more. Moreover, if people distrust the government, they may also distrust the scheme that postpones the access to resources into a distant future, as they may see little guarantee for the present rules to be retained.

By analyzing transitions to work of the benefit recipients of the Chilean program, our paper is the first one providing answer to the above question. We find that the larger the resources on their UISA at the start of the unemployment spell (and thus the lower the potential benefits from SF), the higher the probability of exit from unemployment of benefit recipients that is, the disincentives become smaller as the resources on UISAs become larger. We also find that for persons not using solidarity fund because they are not entitled to, the amount of accumulation on the UISA does not affect hazard rate from unemployment. Had individuals treated those resources as solidarity funds, they would have lowered their probabilities of exit from unemployment (as empirical evidence elsewhere suggests) since our results show no such effects, this is additional evidence that the individual nature of the accounts reinforces work incentives.

These results thus corroborate theoretical predictions about the effects of UISAs. In line with many other studies, our other results also confirm the disincentive effects of solidarity funding. The organization of the paper is as follows. Section 2 provides a background by summarizing the literature on the UISAs and describing the Chilean unemployment benefit program. Section 3 describes the data, formulates the empirical strategy to identify incentive effects of the Chilean program. Section 4 analyses the determinants of opting for the actual use of the SF among those that are entitled to do so. Section 5 presents the results of the estimation of hazard rate models of job finding rates that identify work incentives under the Chilean program. Section 6 concludes. 


\section{Previous studies on UISAs and institutional background}

\subsection{Overview of studies on UISAs}

According to theoretical modeling, the main rationale and key advantage of the UISA system as an alternative to the traditional UI system is its potential of improving the incentives of employed workers and job seekers while conceivably providing the same protection as traditional UI. As shown by several theoretical papers, UISAs would radically change workers incentives (Orszag and Snower, 2002; Orszag et al, 1999). By internalizing the costs of unemployment benefits, the UISA system avoids the moral hazard inherent in traditional UI. Orszag et al (1999) also recommend a comprehensive vs. a piecemeal approach when introducing savings accounts. They warn that a potential complementarity problem exists if the savings account is not set up for multiple uses: under the traditional unemployment system, workers who have built up substantial resources in their pension accounts have the incentive to withdraw from the labor force and claim unemployment benefits until they retire. Setting up an integrated savings account reduces such incentives. There are also other advantages of the "Integrated Unemployment Insurance System." By combining several risks under one program, the system can offer not only superior provision of insurance and thus consumption smoothing, but also to significantly reduce disincentives as compared to the traditional UI system. For example, Stiglitz and Yun (2005) analyze a system in which a personal unemployment savings account is combined with pension program, allowing workers to borrow against their future wage income to finance unemployment benefits. They argue that integration of several social insurance programs with a pension program through an individual account is desirable unless the risks are perfectly correlated.

Empirically, UISAs are still largely uncharted territory, and to best of our knowledge, except for the current study UISAs potential to cure the moral hazard problem associated with UI have not been studied yet. In a rare empirical study of UISAs, Kugler (2005) examines the effects of the 1990 conversion of Colombias severance pay program into a funded severance pay with individual accounts. She finds that the lions share of the costs of the transfer that firms make to individual workers accounts (7587 percent) shows up as a reduction in wages. She also finds that, in accordance with theoretical predictions, the conversion increased both firing and hiring. Her work does not shed light on the effects 
of UISAs on job-search incentives, though. Margolis (2008) studies how UISAs in Brazil affect job finding rates but he uses household surveys which provide information about potential eligibility to UISA and not about actual use. Faced with the dearth of empirical possibilities, several researchers have resorted to simulations, focusing on the following viability issue. By their very design, UISAs rely on intertemporal pooling of resources of individuals so as to be able to eliminate (or, in some versions, restrict) pooling across individuals. But if a significant proportion of workers cannot generate sufficient savings to draw upon during their unemployment spells, such a system may be non-viable. In other words, if unemployment is concentrated among a group of workers, these workers may not be able to finance their unemployment benefits by their own savings.

To investigate the viability of the system, Feldstein and Altman (1998) simulated the working of the UISA system for the U.S. In their simulations, the level and duration of benefits provided by the UISA system are completely the same as under the current UI system. They assume that the UISA benefits are financed by individual, interest-bearing UISA, to which workers contribute 4 percent of their wages. At retirement, a positive account balance is added to a pension account, and a negative balance is forgiven. Their simulations show that (i) over a 25 year period, only a small proportion of workers (5-7 percent) end their working life with negative balances (these estimates are conservative in the sense that they do not account for any behavioral responses to changes in incentives), and (ii) the cost to taxpayers is reduced by more than 60 percent. Feldstein and Altman thus conclude that the UISA system is a viable alternative to the standard UI system.

Applying a methodology similar to Feldstein and Altman (1998), Fölster (1999, 2001) used Swedish panel data to simulate the effects of an introduction of a savings account system, integrating unemployment benefits with sickness benefits, maternity leave, child support, welfare, rent support and disability benefits. His simulations show that 15 to 17 percent of all individuals would be confronted with a negative terminal balances on their savings accounts, and there would be a reduction in taxes by about 30 percent. Applying a similar simulation approach to Slovenias UI system, Vodopivec (2010) shows that the UISA system is a viable alternative to a modest, but not generous UI system. Under the modest regime, only one quarter of workers end their working life with negative cumulative balance and 43 percent ever experience a negative UISA balance; in contrast, under the generous regime, the respective numbers are much larger. Finally, using Danish data, 
Bovenberg et al. (2008) find that about three-fourths of the taxes levied to finance public transfers actually finance benefits that redistribute income over the life cycle of individual taxpayers rather than redistribute resources across people. From this the authors conclude that savings accounts can enhance labor market incentives at low costs in terms of a more unequal distribution of lifetime incomes.

\subsection{Chilean unemployment benefit program}

In October 2002, Chile introduced a program of unemployment insurance that provides benefits through a combination of individual accounts and solidarity funding. Prior to this system there was practically no unemployment benefits program except for a very modest and scarcely used unemployment subsidy administered at the local (municipal) level. The system is mandatory for all wage and salary workers older than 18 when they start a new appointment in the private sector (public sector workers, as well as apprentices, domestic servants, and self-employed do not participate in the system). Workers can also join voluntarily, but there have been few such enrolments (by the end of 2008, they represented less than 2 percent of total membership). Because enrolment is mandatory for all workers who start new jobs and because only a small share of workers enrolled voluntarily, young and more mobile workers are overrepresented in the program, as are industries that hire such workers (such as construction, agriculture and retail trade). Workers under open-ended contracts contribute $0.6 \%$ of their monthly salary to their UISAs, which is complemented by $1.6 \%$ contribution by the employer; the employer must also pay a contribution of $0.8 \%$ of the workers taxable earnings to the SF. Furthermore, The Chilean government makes an annual contribution to the SF of approximately 12 Million US dollars. For workers with fixed-term contracts, the employer pays a 3 percent contribution to their UISAs. Because workers with fixed-term contracts are, by law, excluded from the access to solidarity funding, in continuation we focus on workers with open-ended contracts.

By August 2008, 5.7 million workers enrolled in the program (that is, had their contributions paid at least once), and 2.9 million of them contributed that month. About 58 percent of contributors hold an open-ended contract, and two thirds are men. By September 2008, a total of 3.5 million benefit claims were filed (with some workers filing more that one claim), of which three-quarters by fixed-term workers. Of the 750,000 claims made by workers who became unemployed under an open-ended contract, only about 100,000 were 
financed partly by the SF. This can be explained by both a small proportion of open-ended contracts satisfying SF eligibility criteria and by the fact that only about half of the workers who qualified chose to do so. Note that workers can reject the access to the SF, in which case they finance their benefits exclusively out of their UISAs (see below about reasons that may lead workers to do so).

Eligibility conditions, as well as the level of benefits and the potential benefit duration, differ for the schedule based on "withdrawals from UISAs only" and the schedule based on "withdrawals from UISAs and SF." For the option of "withdrawals from UISAs only," there are only two starting eligibility conditions: payment of 12 monthly contributions, either continuously or non-continuously, and being unemployed (regardless the reason since benefits are also paid to workers who separate voluntarily). The potential benefit duration (number of maximum monthly payments) is determined by the length of the contribution period the number of years and fraction over 6 months that the worker has contributed, with a maximum of 5 withdrawals. The level of benefit is determined by the accumulated balance in the account. For 12 to 18 contributions, all money accumulated in the UISA is withdrawn in one payment; for contributions beyond 18, the benefit is level is determined by distributing the UISA balance over the potential benefit duration (see Table 1). Note that the recipients withdraw all the funds accumulated in the individual account in each unemployment event, as long as they remain unemployed sufficiently long.

For the option "withdrawals from UISAs and the SF," the following starting eligibility criteria apply: (i) 12 months of continuous contributions to the SF in the period immediately prior to the dismissal; (ii) non-fault dismissal (economic reasons or force majeure); (iii) insufficient UISA balances to fund the benefit as stipulated by the law; and (iv) unemployment status. To keep eligibility status under this option, recipients must pay monthly visits to Municipal Employment Offices (OMILs) and they have to be prepared to accept training programs or job offers provided by these offices paying at least $50 \%$ of their preunemployment wages. The level of the benefit is determined by a replacement rate (as a proportion of beneficiary's average wages in the last 12 months), with inflation-adjusted limits on the minimum and maximum. The replacement rate starts at $50 \%$ in the first month and decreases by 5 percentage points each subsequent month, reaching $30 \%$ in the 5th (last) month. ${ }^{2}$ Benefits are first drawn from the beneficiarys UISA and, upon exhaust-

\footnotetext{
${ }^{2}$ After the last month, workers may be entitled to welfare benefits, but these are means-tested and very
} 
ing the account, from the SF. Access to the SF is only granted for two unemployment spells per five years. Open-ended contract workers who are dismissed for the same reasons that make them qualify for the SF are entitled to receive severance payment in the amount of one monthly salary per year worked, with a maximum of 11 monthly salaries and a minimum length of contract of one year. This is a lump sum payment. ${ }^{3}$

To illustrate the incentives for unemployed in the Chilean UB system, Figure 1a shows how the duration of contributions to the system affects the starting replacement rate (see above about the rules that determine subsequent ones). ${ }^{4}$ After contributing for 12 months, the individual is entitled to a replacement rate of $27 \%$. Larger number of contributions gradually increases the replacement rate to $39 \%$, but after 18 months of contributions (when the accumulation of contributions equals $42 \%$ of the beneficiary's wage) the benefit is distributed over 2 months, amounting to $22 \%$ in the first month and $23 \%$ in the second. After 30 months the benefit is distributed over 3 months, etc. Figure $1 \mathrm{~b}$ shows the evolution of the replacement rate over the unemployment spell of a worker who starts collecting unemployment benefits after paying 36 (monthly) contributions, both for "withdrawals from UISAs only" and "withdrawals from UISAs and SF" schedules. Under "withdrawals from UISAs only," unemployment benefits last for three months; in contrast, under "withdrawals from UISA and SF," unemployment benefits last 5 months, and the replacement rate is higher. Clearly, there is a gain from accessing SF both in terms of higher replacement rate targeted. To qualify a household must be "enrolled" in a system were a Social Worker visits the home and assesses its socioeconomic status. Several characteristics of the household and its members are collected in this registry and a formula converts them to a point score. Households below a certain score (signifying approximately the first quintile of income distribution) are eligible for benefits. Therefore a household with an unemployed member that exhausts the UI Solidarity Fund must first fall into poverty before applying for welfare benefits.

${ }^{3}$ However, it is not clear how much of it actually gets paid. Anecdotal evidence suggests that employers may reach agreement upon dismissal to pay less than the legal amount or change the cause of dismissal to avoid payment. Also, if the firm is dismissing because of economic hardship or even bankruptcy it is doubtful how much can workers recover, although they have preeminence before other creditors. In part for this reason, when the UI system was implemented, the law established that employers may reduce the amount of Severance Payment in the equivalent of the Individual Account balance attributed to the employers contributions ( $1.6 \%$ of monthly salaries). In other words, this is a way of pre-funding part of the severance payment that would be made by the employer.

${ }^{4}$ This concerns a worker with a monthly salary of 135,000 making a monthly contribution of $2970(2.2 \%)$ and earning a $0,5 \%$ monthly rate of return. 
and longer potential benefit duration.

\section{Description of data and empirical strategy}

\subsection{Data}

Our study relies on administrative records of the contribution histories of and benefits paid to the workers participating in the Chilean unemployment benefit program. These records are maintained by the Superintendencia de Pensiones, the agency in charge of the regulation and supervision of the program. We selected samples of males and females born between 1958 and 1981 who lost a permanent job before 2007. We focus on the duration of their first unemployment spell. This gave us samples of 49,702 men and 26,276 women. For these prime age individuals, apart from their records of contributions and benefits, we also have information on UISA account balance, educational attainment, and region of residence, and sector of activity of their pre-unemployment employer. ${ }^{5}$

Table 2 provides the summary statistics of this sample, by sex and entitlement to access SF. While the characteristics of the sample differ between men and women, they are rather similar for those entitled and not entitled to access SF (except for unemployment duration); 68 percent of men and 63 percent of women has no right to access the SF. The average number of potential withdrawals from UISAs ranges from 1.7 to 1.9. For men not entitled to use the SF the average unemployment duration including incomplete spells is equal to 8.1 months, and the average duration of completed unemployment spells is 5.6 months. Men who are entitled to use the SF on average have a longer unemployment duration; 9.5 months for all spells and 6.7 months for completed spells. Women stay unemployed for a longer period; for them the average unemployment duration including incomplete spells is about 13 months, while the average duration of completed unemployment spells ranges from 7.5 to 8.3 months.

\footnotetext{
${ }^{5}$ Note that the samples do not contain personal identifiers. Also note that we removed individuals who have 5 potential withdrawals from their individual accounts from the sample since this concerns only a few individuals.
} 


\section{$3.2 \quad$ Empirical strategy}

All unemployed workers in our sample have access to UISAs. In terms of incentives for job finding they differ in two dimensions of their access to unemployment insurance. First, unemployed differ in whether or not they use the SF in addition to their UISA. Some workers use the SF while other workers do not use the SF because they are not entitled or because for whatever reason they choose not to use it. Second, unemployed differ in the size of their UISA as measured by the number of potential withdrawals.

Compared to workers who only have access to UISAs, for workers who use the SF there are clear disincentives for job finding. Workers who have to rely on their UISAs stand to lose more from being unemployed since they internalize the costs of being unemployed. Therefore with only UISAs unemployed have an incentive to search harder for jobs i.e. take less leisure while unemployed (Orszag and Snower, 2002). ${ }^{6}$

To identify the incentive effects that UISAs accumulations have on job-finding rates, we exploit the leverage provided by exogenous variations in such accumulations. Even if they face a common withdrawal schedule (the same replacement rate and potential benefit duration) beneficiaries differ in the amount of accumulated savings in their UISAs in the way that is unrelated to their individual characteristics. Indeed, given that the system is still in the starting period, this amount is determined, above all, by a layoff decision of the employer, the timing of which triggers the enrollment of the worker in the unemployment benefit program and thus determines the length of the contribution period and hence the amount accumulated on UISAs. Workers who rely on UISAs will internalize the costs of their unemployment. This implies that the size of their fund will not affect their job finding rate. $^{7}$ There are also other incentives that affect job search behavior. Workers who use

\footnotetext{
${ }^{6}$ To compare incentives under Unemployment Accounts (UA) and regular Unemployment Benefits (UB), Orszag and Snower (2002) created a two-period model based on discounted lifetime utility maximization. Under the UA, they assume that workers are required to make ongoing contributions to their unemployment accounts, and the balances in these accounts are available to them during periods of unemployment. In contrast, under the UB each unemployed worker receives an exogenously given unemployment benefit that is financed through a payroll tax.

${ }^{7}$ Chetty (2008) distinguishes between a "moral hazard effect" of UI benefits because of the distortions in the marginal incentives to search and a "liquidity effect" for unemployed because they are liquidity constraint and would otherwise be forced to accept suboptimal jobs. Both effects lead to longer unemployment durations but have different welfare implications. The moral hazard effect is welfare-reducing, the liquidity effect is welfare-enhancing. Note that we assume that the access to the SF does not introduce "liquidity
} 
the SF can draw benefits for a maximum of 5 months. This will introduce non-stationarity in their job search behavior. As the date approaches when benefits expire, unemployed workers may increase the intensity of their job search or reduce their reservation wage thereby increasing the rate of job-finding (Mortensen, 1977). Workers who do not use the $\mathrm{SF}$ will not have this incentive to increase their job finding rate in the first months of their unemployment spell.

As indicated before, the Chilean program is a "hybrid" system. Beneficiaries using the SF fall under the "mixed" regime, because their benefits are paid partly from the individual accounts and partly from the SF. But for the beneficiaries of the latter group, one can expect that the lower the share of benefits that is potentially paid from SF (the higher the proportion of benefits financed by their UISAs), the fewer the disincentives they have in their job search behavior.

Under the design features of the Chilean unemployment benefit program, we can empirically investigate the potential incentive effects of the UISAs. For beneficiaries using SF we expect during the potential benefit duration period (the first five months of unemployment) that they will be less likely to exit from unemployment than beneficiaries not using SF. As the month of benefit expiration comes closer their job finding rate will increase to reach a maximum shortly before benefits expire. Moreover, applying the same logic of internalization of costs, the larger the share of potential benefits that they can finance out of their UISA at the start of the unemployment spell, the more likely they will exit from unemployment. In other words, employment disincentives become smaller as the resources obtainable from SF become smaller). For beneficiaries not using SF we expect that the amount of accumulation on their UISAs will not affect their exit rate from unemployment, nor will their time pattern of exit from unemployment be affected by the payment of unemployment benefits, as the costs of unemployment benefits is completely internalized.

Below, we also address the selection issues that arise because some beneficiaries choose to use the SF while other choose not to use the SF. These two groups may differ in some important unobservable characteristics which also affect the exit rate from unemployment. We start our empirical analysis by investigating the determinants of the SF use, and proceed effects". Whether this is indeed the case is an empirical question to which our analysis will provide an answer. 
with the analysis of the job-finding rate.

\section{Determinants of solidarity fund use}

The richness of the design of the Chilean program allows the empirical investigation of incentive effects of the program along several dimensions, and the present paper focuses on two of them. The central issue addressed is the impact of the program on re-employment incentives of the program, more precisely, on the job finding rate. The other issue addressed by the paper is the driving forces influencing the decision to actually use SF, given formal eligibility. While there are apparent gains from gaining access to SF (both higher replacement rate and longer potential benefit, see above), in practice only about half of eligible workers decided to do so - certainly a puzzling result that deserves consideration. In this section we examine the factors that influence this decision, focusing on the number of potential UISAs withdrawals an indication of the size of the individual savings available to finance unemployment benefits as a possible determinant.

While the entitlement to use SF is not a matter of choice, the actual use of SF is. As described above, eligibility to use the SF is determined by technical rules that individuals cannot affect (see above on the starting eligibility criteria for "withdrawals from UISAs and the SF" schedule). In contrast, there is a clear monotonic relationship between the actual use of the SF and the number of potential withdrawals from UISAs: the higher the number of potential withdrawals, the lower the use of the SF the finding that applies to both men and women (Table 3). For example, among the men who are entitled to use the $\mathrm{SF}$ and having one potential withdrawal, $61 \%$ uses the SF, and among men entitled to use SF and having four potential withdrawals, only $27 \%$ uses the SF.

To investigate how the number of potential withdrawals from the UISAs and personal characteristics affect the use of the SF conditional on entitlement we performed a logit estimates. Thus $\operatorname{Pr}(y)=\Lambda\left(x^{\prime} \gamma\right)$, where $\Lambda$ is an indicator of the logistic cumulative distribution function, $y$ indicates whether or not an individual uses the SF, $x$ is a vector of explanatory variables, and $\gamma$ is a vector of parameters. ${ }^{8}$ Conditional on the observed char-

\footnotetext{
${ }^{8}$ The $x$ refers to a vector of personal characteristics and variables related to the unemployment benefit program presented. These variables include dummy variables for the number of potential withdrawals from the UISA (3), educational attainment (3), industry (15), region (14), birth year cohort (4) and year of entrance into unemployment (2). For simplification a subscript referring to individual is omitted.
} 
acteristics, parameter estimates show that the higher the number of potential withdrawals (that is, the larger individual accumulations and hence the lower the potential gain from using the solidarity fund), the lower the probability of the use of the SF (Table 4). This has a simple, intuitively clear interpretation: the more the unemployed can rely on their own funds, the less likely they apply for the SF, because the usage of SF is associated with certain costs, above all, the transaction costs of contacting the employment offices and of satisfying continuing eligibility requirements (that include accepting suitable job offers) and possible stigmatization of persons using employment office services. Other results show significant effects from industry, region, educational attainment, and birth cohort. Moreover, the results show that individuals who entered unemployment in 2005 and 2006 where less likely to use the SF than those in previous years.

\section{$5 \quad$ Incentive effects and job finding rates}

In this section we report the parameter estimates of mixed proportional hazard rate models that allow us to investigate the validity of the predictions about the job-finding incentives generated by the Chilean unemployment benefit program. To obtain a better understanding of the job-finding process, we start with graphical analysis of job finding rates and survival in unemployment for key groups of beneficiaries.

Figure 2 shows the job finding rates and survival rates for prime age men, separately for workers who are not entitled to access SF, for those who are entitled but do not use the SF and for those that use the SF. The main differences occur at the start of the unemployment spell, with the job-finding rate for workers not using the SF exceeding the job-finding rate of workers who use the SF. In fact, the job finding rate of the latter group is increasing over the first 5 months of unemployment, and from the sixth month onward the differences in job finding rate between the three groups become small (Figure 2a). Consistent with above, the survival function shows that workers who use the SF stay in unemployment longer than workers who do not use the SF (Figure $2 \mathrm{~b}$ ).

Figure 3 gives a similar overview of job finding rates and survival rates for prime age women. The exit rates are lower but the patterns are very similar to those of men. Women who use the SF have a low and increasing exit rate in the earlier months of unemployment. Women who do not use the SF initially have a higher unemployment exit rate but after 
about 5 months their exit rates are similar to the exit rate for women who use the SF.

\subsection{Econometric modeling of the job-finding rate}

We analyze transitions from unemployment using mixed proportional hazard rate models. We distinguish three groups of workers which we indicate with subscript $j$. First, there is a group of workers who are not entitled to the use of the SF. The second group of workers uses the SF while the third group of workers is entitled but doesn't use the SF. In our model the job-finding rate at time (unemployment duration) $t$ conditional on observed characteristics $x$ and unobserved characteristics $u_{j}$ can be specified as:

$$
\theta_{j}(t \mid x)=\lambda_{j}(t) \exp \left(x^{\prime} \beta_{j}+u_{j}\right), \quad j=1,2,3
$$

where $x$ contains the same variables as in the previous analysis of the determinants of $\mathrm{SF}$ use, $\beta_{j}$ is a vector of parameters and the $\lambda_{j}(t)$-functions represent individual duration dependence. Individual duration dependence is modeled in a flexible way by using step functions:

$$
\lambda_{j}(t)=\exp \left(\Sigma_{k} \lambda_{j, k} I_{k}(t)\right)
$$

where $k(=1, \ldots, N)$ is a subscript for time-intervals, and $I_{k}(t)$ are time-varying dummy variables that are one in $N$ subsequent time-intervals. The parameter $k$ measures the pattern of duration dependence. The conditional density function of the completed unemployment duration $t$ can be written as

$$
f_{j}\left(t \mid x, u_{j}\right)=\theta\left(t \mid x, u_{j}\right) \exp \left(-\int_{0}^{t} \theta_{j}\left(s \mid x, u_{j}\right) d s\right)
$$

Finally, the unobserved heterogeneity is assumed to follow a discrete distribution with two points of support $u_{j}^{a}$ and $u_{j}^{b}$, with $\operatorname{Pr}\left(u_{j}=u_{j}^{a}\right)=p_{j}$ and $\operatorname{Pr}\left(u_{j}=u_{j}^{b}\right)=1-p_{j}$ and $p_{j}$ has a logit specification: $p_{j}=\exp \left(\alpha_{j}\right) /\left(1+\exp \left(\alpha_{j}\right)\right)$. The two points of support are random effects assumed to be orthogonal to the observed characteristics of the individuals. Because we also estimate a constant we normalize $u_{j}^{a}=0$. We remove the unobserved components by taking expectations:

$$
f_{j}(t \mid x)=E_{u_{j}}\left[f_{j}\left(t \mid x, u_{j}\right)\right]
$$

The parameters are estimated separately for men and women for each of the three groups of benefit recipients. We use the method of maximum likelihood, taking into account 
that some durations are right-censored while the complete durations are known in discrete months.

The above model is suitable to estimate the job finding rate for the group of beneficiaries not entitled to use SF. For the group that is entitled to use SF, however, we have to account for the fact that it comprises both individuals who decided to use SF and individuals who decided not to use SF, and that this decision may not be exogenous to the exit rate. It may well be the case that individuals who expect to be unemployed for a long period are more inclined to use the SF than those who expect to be unemployed for short period (see also Berstein et al., 2007). Thus it may be the case that unobserved worker characteristics affect both the exit rate and the inclination to use the SF. We address this issue below.

\subsection{Parameter estimates}

We estimate the parameters of our mixed proportional hazard models separately for males and females. Table 5 contains the parameter estimates for males, table 6 shows the results for females. We report only relevant parameter estimates. For beneficiaries who were not entitled to use the SF, the number of potential withdrawals has no effect on the job finding rate. This means that the UISA accumulation of beneficiaries relying on UISAs only does not affect exit rates. Moreover, the time pattern of the job finding rate as determined by the coefficients of monthly dummies shows no correspondence to payment of unemployment benefits. For both men and women these coefficients show strong and monotonic negative duration dependence. Figure 4 provides a graphical representation of the pattern of duration dependence.

For the beneficiaries who used the SF, the results show that the higher accumulation of the UISAs, the higher the job finding rate, as evident from the positive coefficients of the dummy variables for the number of potential withdrawals. Moreover, there is a monotonous increase in the job finding rate in the first months of unemployment, and a steady reduction of the exit rate thereafter, for both men and women. This is indeed a pattern consistent with (dis)incentives related to the receipt of benefits, as the job finding rate is lower at the beginning of the unemployment spell (reflecting the "waiting" effect moral hazard connected with the use of SF), the effects in place over the period of potential receipt of benefit ( 5 months in this case).

For the group of beneficiaries not using the SF because they chose so, the parameter 
estimates are very similar to those not using SF because they did not qualify for the use SF: for men job finding rates are unaffected by the number of potential withdrawals, and the exit rates for both men and women show negative duration dependence throughout the unemployment spell.

We find that for all groups unobserved heterogeneity is present, and conditional on the observed characteristics and the pattern of duration dependence we identify two groups of workers, one with high and one with low job-finding rates. For both men and women the first group with a high job-finding rate is always larger than the second group with a substantially lower exit rate. For men the distribution of the unobserved heterogeneity is very similar across the three groups of workers. For males not entitled to SF conditional on observed characteristics and the pattern of duration dependence there is a group of $75 \%$ who have a high job finding rate, while $25 \%$ has a substantial lower job finding rate. For males opting for SF and males not opting for SF these groups are $73 \%$ and $27 \%$. For females there are clear differences in the distribution of unobserved heterogeneity. For females not entitled to SF and females opting for SF there is a group of 58-59\% who have a high exit rate and a group of $41-42 \%$ who have a much lower exit rate. However for females not opting for SF there is a group of $88 \%$ who have a high job finding rate and a group of $12 \%$ who have such a low job finding rate that this converges to zero. This would imply that $12 \%$ of the females will never find a job, which might be attributed to these females having left the labor force rather than remaining unemployed looking for a job. The fact that we are able to identify unobserved heterogeneity indicates that the observed personal characteristics are insufficient to cover all determinants of the exit rates out of unemployment.

\subsection{Sensitivity analysis}

As indicated before, workers who decided to use SF and workers who decided not to use $\mathrm{SF}$ even if they were entitled to do so may be different from each other in terms of their labor market position. If the decision to use the $\mathrm{SF}$ is not exogenous to the job finding rate parameter estimates may be biased. To address this concern of potential selectivity in the use of the SF, we investigated whether the distribution of unobserved heterogeneity is the same for workers who were entitled to use the SF and opt to use it as compared to those 
who were entitled to use the SF but chose not to use it. ${ }^{9}$ To investigate this we estimate a joint model for the job finding rates of workers in groups 2 and 3 imposing $u_{2}^{b}=u_{3}^{b}$ and $\alpha_{2}=\alpha_{3}$. The lower part of tables 5 and 6 shows the relevant estimation results. For males the restricted model is not significantly different from the separate estimates. The choice to use the SF is affected by observed and unobserved personal characteristics. Similarly the job finding rates are affected by observed and unobserved characteristics. We do not find that the unobserved characteristics affecting the job finding rates are correlated with the use of the SF, i.e. we cannot reject the hypothesis that there is no selectivity in the use of the SF.

For females the situation is different. The distribution of unobserved heterogeneity is different for females who use the SF and females who are entitled to use the SF but don't use it. Apparently for women there is selectivity in the choice of using the SF. Women who choose to use the SF on average has a weaker labor market position or is less motivated to find a job than the women who are entitled to use the SF but opt not to do so. The latter group is the "outlier" as the other two groups have a similar distribution of unobserved heterogeneity.

As an alternative to the number of potential withdrawals from the UISA we also investigated how the (logarithm of the) UISA account balance (AB) at the start of the unemployment spell affects the job finding rates. The relevant parameter estimates are shown in Table 7. The first column shows that for males who use the SF the elasticity of the account balance with respect to the job finding rate is 0.29 . The second column shows that for males who do not opt to use the SF the account balance doesn't affect the job finding rate. The bottom part of the table shows that for males we cannot reject the hypothesis that there is no selectivity in the use of the SF. All in all, these alternative estimates are very similar to the baseline estimates shown in Table 5 . The similarity between the estimates in Tables 7 and 6 also holds for women. For women who use the SF the elasticity of the account balance with respect to the job finding rate is 0.37 . For women who opt not to use the SF the elasticity is 0.14 , substantially smaller but still significantly different from zero. Also for these alternative estimates we reject the hypothesis that there

\footnotetext{
${ }^{9}$ This set-up is similar to the one used by Bover et al. (2002) who compare hazard rates for unemployed workers without benefits with hazard rates for workers with benefits. They investigate whether having benefits or not is orthogonal to the exit rates from unemployment by estimating a model with a bivariate heterogeneity distribution.
} 
is no selectivity in the use of the SF.

\section{Concluding remarks}

This study examined work incentives generated under the Chilean unemployment benefit program. This is a unique, innovative program combining social insurance with selfinsurance in the form of savings accumulated on UISAs, designed so as to mitigate the moral hazard problem present in traditional UI programs. The study estimated the determinants of the job-finding rate of unemployment benefit recipients and, taking advantage of the design features of the program, was able to identify work incentives generated by the program, separately by the UISAs and SF component of the program.

Our results render a strong support to the idea that UISAs can improve work incentives. We find that for beneficiaries that take advantage of SF, the probability of exit from unemployment of benefit recipients is positively associated with the amount of savings on recipients UISA at the start of the unemployment spell, and that there is no such association for the beneficiaries that rely on their own UISAs savings only a clear sign that individuals internalize the costs of unemployment benefits and treat UISAs resources as their own. Our results also reveal the unemployment duration dependence pattern consistent with moral hazard effects, for beneficiaries using SF, and the pattern free of such effects, for beneficiaries relying on UISAs only. Interestingly, because the total benefit does not depend on the source of funding, the disincentive effects we find for beneficiaries that use SF should be totally attributed to moral hazard behavior, as opposed to the "liquidity" effects of benefits (compare Chetty, 2008).

The above findings have strong policy implications. By providing empirical support to the so far only theoretically grounded claims that UISAs can reduce work disincentives connected by OECD-style UI programs, they provide a strong endorsement for ideas of reforming traditional UI programs by introducing an UISAs component (for the U.S., see recent proposals by Kletzer and Rosen, 2006, and in particular, Kling, 2006). ${ }^{10}$

Our study also prompts questions about the design of the UISAs program. Our results

\footnotetext{
${ }^{10}$ The introduction of UISAs seems particularly attractive for developing countries, because they face a large informal sector and they lack the administrative capacity needed for an effective implementation of the standard UI system - particularly of checking continuing eligibility conditions that requires monitoring of job-search behavior and of labor market status.
} 
show that participants in the Chilean program face work disincentives through the SF component of the program, although the vast majority of benefits are not paid using the SF. Hence the question of what is the appropriate scope for the SF component and, moreover, what is the scope for monitoring and sanctions in such a system, as our results also show that the likelihood of using SF depends on the perceived costs of using SF. Another open question relates to the relative size of the UISA and SF components. In fact, our results point to an important interrelation between the two, as increasing the UISAs component (perhaps even by partial government matching of contributions) may encourage job-finding rate and reduce the resources needed for solidarity funding.

The answer to these questions, however, does not lie exclusively in the job finding incentives of the program. The ultimate design of any UI scheme must respond to the main objective of smoothing consumption while creating improved conditions for job transitions and even achieving some redistributive impact. To strike the balance between UISAs (which essentially consist on self-insurance) and other forms of risk pooling, such as a Solidarity Fund, policy makers must consider their effects on these outcome variables as well as on the job finding incentives we have studied on this paper. 


\section{References}

- Abbring, J.H., G.J. van den Berg, and J.C. van Ours (2005) The effect of unemployment insurance sanctions on the transition rate from unemployment to employment, Economic Journal, 115, 602-630.

- Acevedo, G., P. Eskenazi, and C. Pagés (2005) The Chilean unemployment insurance: a new model of income support available for unemployed workers? Working Paper, World Bank, Washington D.C.

- Berstein, S., E. Fajnzylber, P. Gana, and I. Poblete (2007) Cinco Años de Funcionamiento del Seguro de Cesantía en Chile, Working Paper, No 23, Superintendencia de Pensiones, Santiago, Chile.

- Bovenberg, A.L., M.I. Hansen and P.B. Sørensen (2008) Individual savings accounts for social insurance: rationale and alternative designs, International Tax and Public Finance, 15, 67-86.

- Bover, O., M. Arellano and S. Bentolila (2002) Unemployment duration, benefit duration and the business cycle, Economic Journal, 112, 223-265.

- Chetty, R. (2008) Moral hazard versus liquidity and optimal unemployment insurance, Journal of Political Economy, 116, 173-234.

- Feldstein, M. and D. Altman (1998) Unemployment insurance savings accounts, NBER Working Paper 6860.

- Ferrer, A.M. and W.G. Riddell (2009) Unemployment Insurance Savings Accounts in Latin America: Overview and Assessment, World Bank Discussion Paper No. SP 910.

- Fölster, S. (1999) Social insurance based on personal savings, Economic Record, 75, $5-18$.

- Fölster, S. (2001) An evaluation of social insurance savings accounts, Public Finance and Management, 1, 420-448.

- Fredriksson, P. and B. Holmlund (2006a) Improving incentives in unemployment insurance: a review of recent research, Journal of Economic Surveys, 20, 357-386. 
- Fredriksson, P. and B. Holmlund (2006b) Optimal unemployment insurance design: time limits, monitoring, or workfare? International Tax and Public Finance, 13, $565-585$.

- Gruber, J. (1997) Consumption-smoothing effects of unemployment insurance, American Economic Review, 87, 192-205.

- Hamermesh, D.S., and D. T. Slesnick (1995) Unemployment insurance and household welfare: microeconomic evidence 1980-93, NBER Working Paper No. 5315.

- Holmlund, B. (1998) Unemployment insurance in theory and practice, Scandinavian Journal of Economics, 100, 113-141.

- Kletzer L. G and H.F. Rosen (2006) Reforming unemployment insurance for the twenty-first century workforce, Brookings Institution, Discussion paper 2006-06.

- Kling J.R. (2006) Fundamental restructuring of unemployment insurance: wage-loss insurance and temporary earnings replacement accounts, Brookings Institution, Discussion paper 2006-05.

- Kugler, A. (2005) Wage-shifting effects of severance payments savings accounts in Colombia, Journal of Public Economics, 89, 487-500.

- Lalive, R., J.C. van Ours, and J. Zweimüller (2006) How changes in financial incentives affect the duration of unemployment, Review of Economic Studies, 73, 10091038.

- Margolis, D.N. (2008) Unemployment insurance versus individual unemployment accounts and transitions to formal versus informal sector jobs, mimeo, Paris School of Economics.

- Mortensen, D.T. (1977) Unemployment insurance and job search decisions, Industrial and Labor Relations Review, 30, 505-517.

- Orszag, J.M., D.J. Snower, and J.E. Stiglitz (1999) The impact of individual accounts: piecemeal vs. comprehensive approaches. Paper presented at the Annual Bank Conference on Development Economics, World Bank. 
- Orszag, M. and D. Snower (2002) From unemployment benefits to unemployment accounts, Discussion Paper no. 532, IZA, Bonn.

- Stiglitz J.E.,and J. Yun (2005) Integration of unemployment insurance with retirement insurance, Journal of Public Economics, 89, 2037-2067

- Van Ours, J.C. and M. Vodopivec (2006) How shortening the potential duration of unemployment benefits affects the duration of unemployment: evidence from a natural experiment, Journal of Labor Economics, 24, 351-378.

- Vodopivec, M. (2004) Income support for the unemployed: issues and options, mimeo, World Bank, Regional and Sectoral Studies Series.

- Vodopivec, M. (2010) How viable are unemployment insurance savings accounts: simulation results for Slovenia, Comparative Economic Studies, forthcoming. 


\section{Figure 1: Replacement rates in the Chilean UB system}

a. Effect of months of contributions on the replacement rate; by month of unemployment

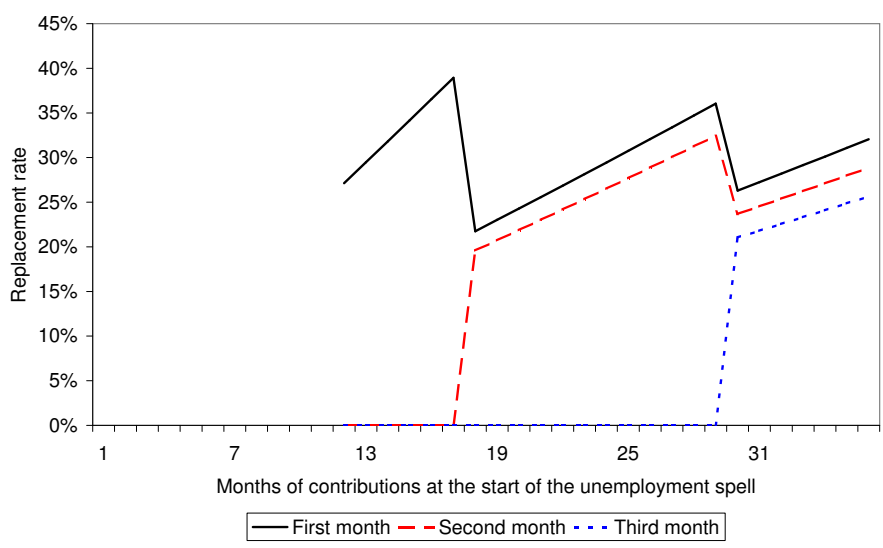

b. Replacement rate by unemployment duration; SF and individual accounts; worker who paid contributions for 36 months

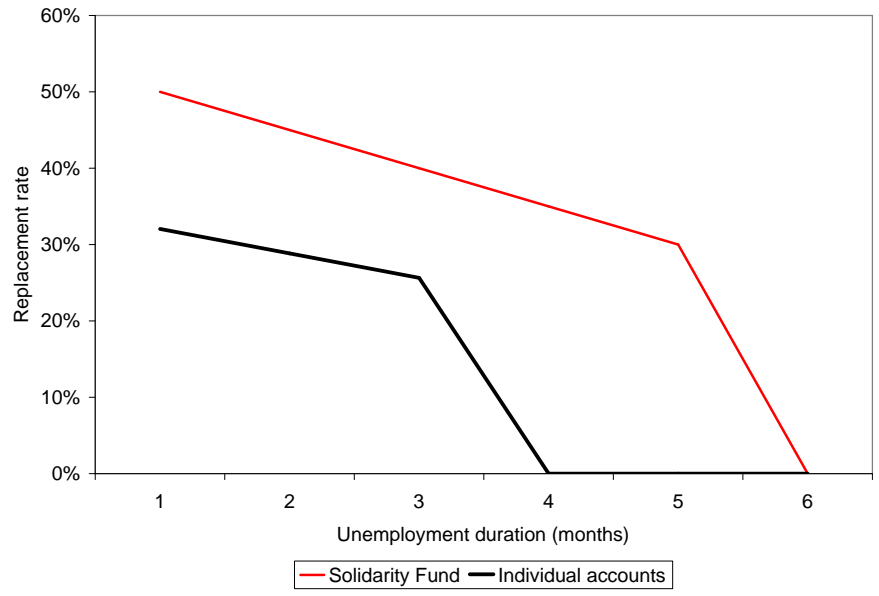


Figure 2: Exit rates and survival rates; prime age males

a. Exit rates out of unemployment

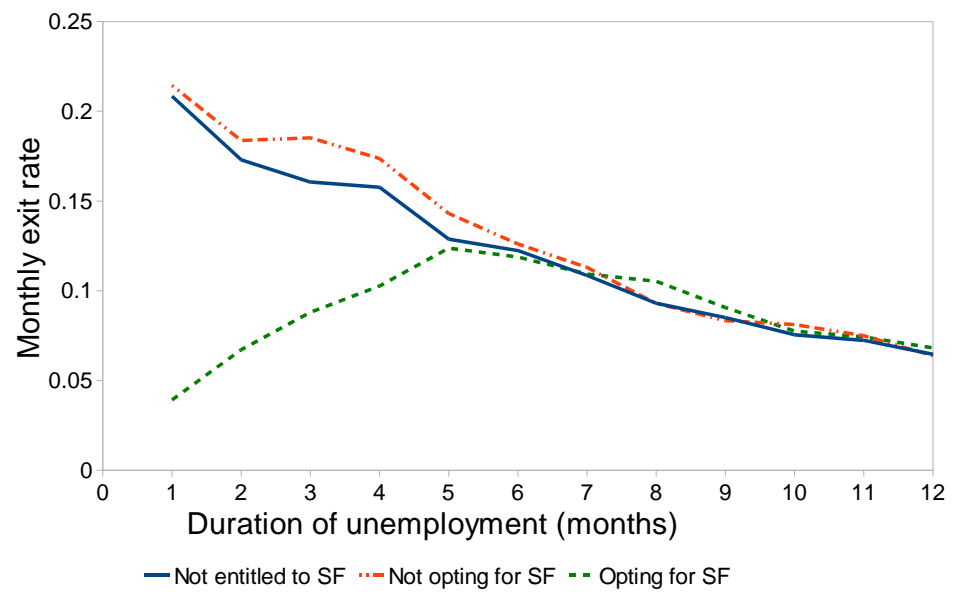

b. Survival rates

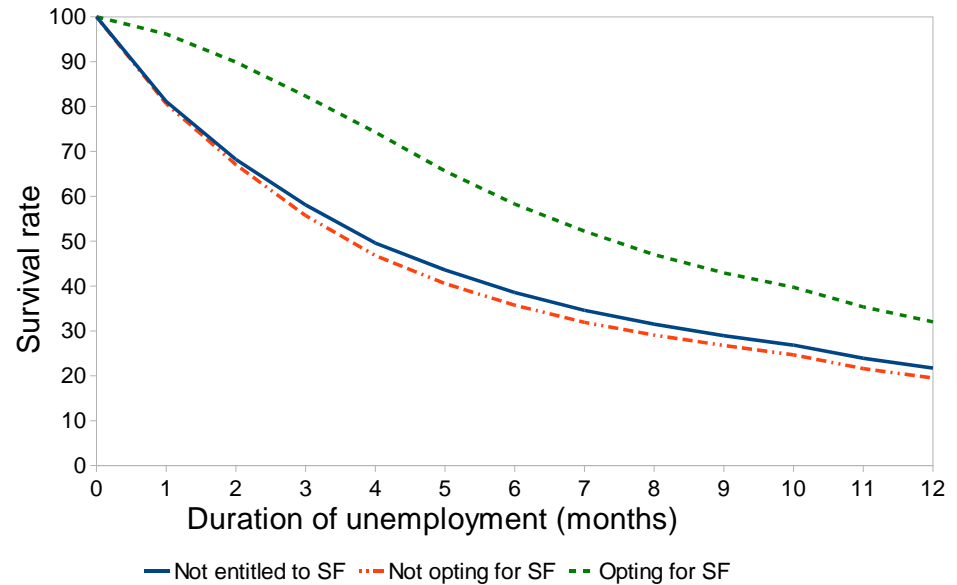


Figure 3: Exit rates and survival rates; prime age females

a. Exit rates out of unemployment

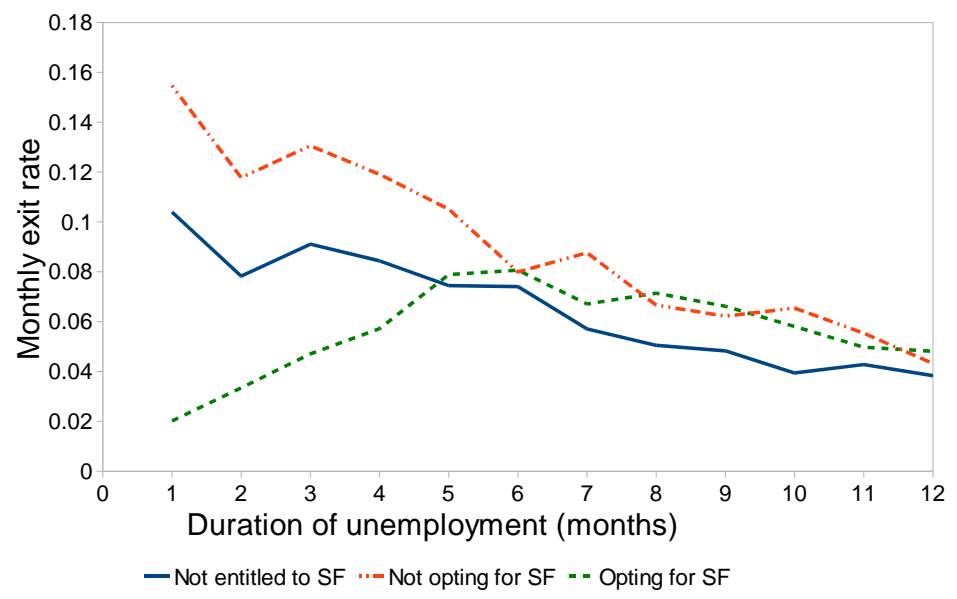

b. Survival rates

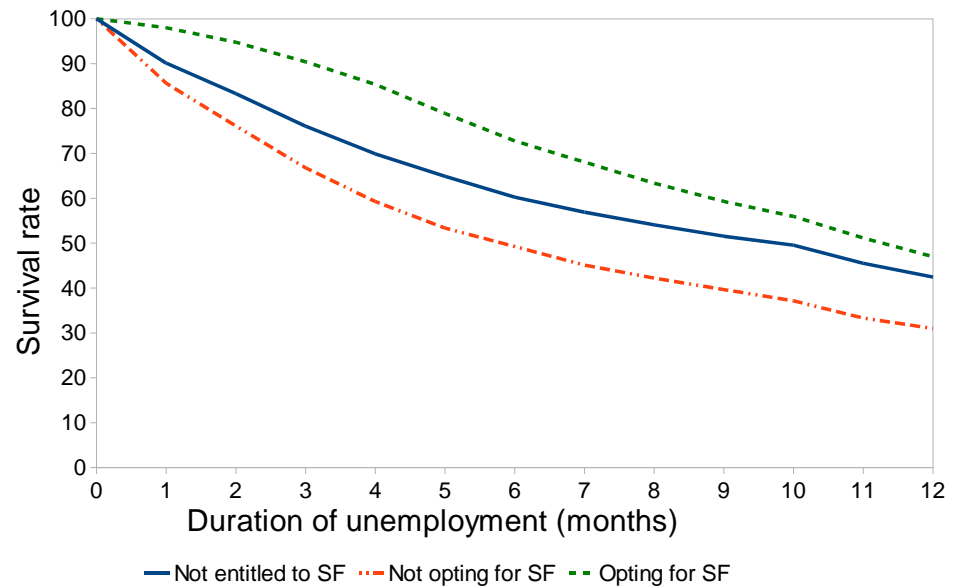


Figure 4: Pattern of duration dependence

a. Males

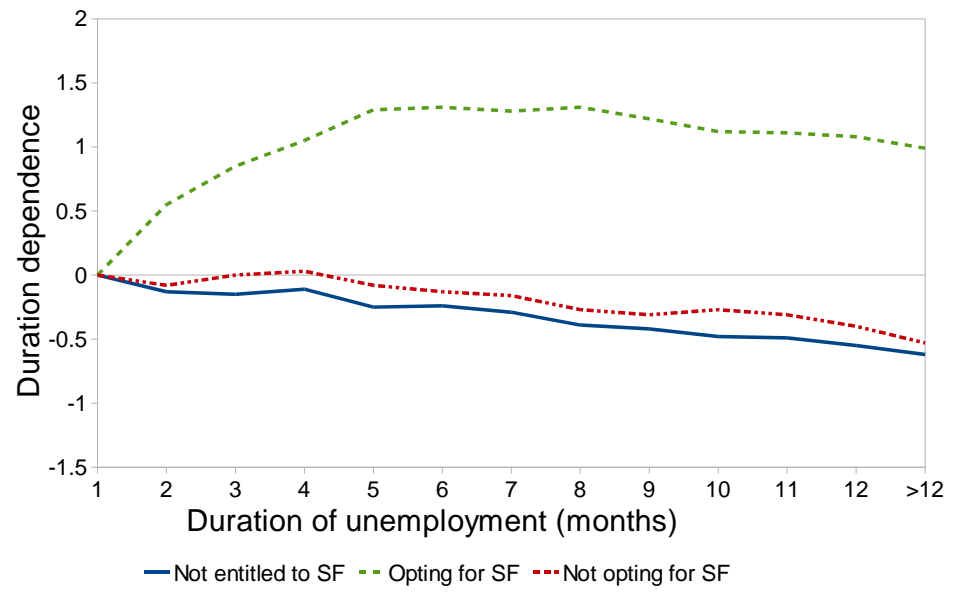

b. Females

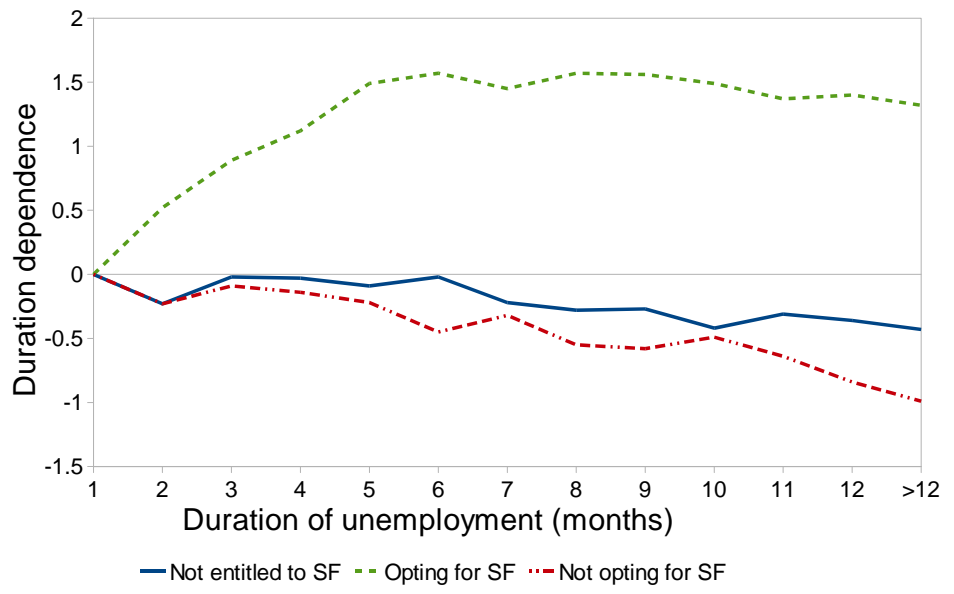




\section{Table 1: Determination of unemployment benefits from UISAs withdrawals}

\begin{tabular}{ccc}
\hline $\begin{array}{c}\text { Years of } \\
\text { contribution }\end{array}$ & $\begin{array}{c}\text { Number of } \\
\text { withdrawals }\end{array}$ & Factor \\
\hline $1-1.5$ & 1 & 1.0 \\
$1.5-2.5$ & 2 & 1.9 \\
$2.5-3.5$ & 3 & 2.7 \\
$3.5-4.5$ & 4 & 3.4 \\
$>4.5$ & 5 & 4.0 \\
\hline
\end{tabular}

Note: The unemployment benefit of the first payment is obtained by dividing the UISAs balance at the time of separation by the factor shown in the second column of the table; the levels in the second to fourth month correspond to $90 \%, 80 \%$ and $70 \%$ of that amount, respectively. The fifth withdrawal equals to the remaining balance on the UISA. 
Table 2: Summary statistics samples of prime age men and women

\begin{tabular}{l|cc|cc}
\hline & Males & Females & \\
\hline & $\begin{array}{c}\text { Not entitled } \\
\text { to use SF }\end{array}$ & $\begin{array}{c}\text { Entitled } \\
\text { to use SF }\end{array}$ & $\begin{array}{c}\text { Not entitled } \\
\text { to use SF }\end{array}$ & $\begin{array}{c}\text { Entitled } \\
\text { to use SF }\end{array}$ \\
\hline Used SF & - & 0.55 & - & 0.69 \\
Potential withdrawals & & & & \\
1 & 0.51 & 0.33 & 0.50 & 0.37 \\
2 & 0.33 & 0.47 & 0.34 & 0.46 \\
3 & 0.14 & 0.17 & 0.14 & 0.15 \\
4 & 0.02 & 0.03 & 0.02 & 0.02 \\
\hline Potential withdrawals & 1.7 & 1.9 & 1.7 & 1.8 \\
Duration (months) & & & & 13.2 \\
Total & 8.1 & 9.5 & 13.1 & 8.3 \\
Completed duration & 5.6 & 6.7 & 7.5 & 9,619 \\
\hline N & 33,909 & 15,793 & 16,657 & 6,574 \\
N - completed duration & 29,027 & 12,980 & 11,077 & \\
\hline
\end{tabular}


Table 3: Entitlement and use of the Solidarity Fund by number of potential withdrawals from the individual account

\begin{tabular}{l|ccc|ccc}
\hline & \multicolumn{3}{|c|}{ Males } & \multicolumn{3}{c}{ Females } \\
\hline $\begin{array}{l}\text { Potential } \\
\text { withdrawals }\end{array}$ & $\begin{array}{c}\text { Entitled } \\
\text { (\% of total) }\end{array}$ & $\begin{array}{c}\text { Used SF } \\
\text { (\% of entitled) }\end{array}$ & $\begin{array}{c}\text { Total } \\
(\%)\end{array}$ & $\begin{array}{c}\text { Entitled } \\
\text { (\% of total) }\end{array}$ & $\begin{array}{c}\text { Used SF } \\
\text { (\% of entitled) }\end{array}$ & $\begin{array}{c}\text { Total } \\
(\%)\end{array}$ \\
\hline 1 & 23 & 61 & 45 & 30 & 76 & 46 \\
2 & 40 & 57 & 38 & 44 & 70 & 38 \\
3 & 36 & 43 & 15 & 39 & 52 & 14 \\
4 & 35 & 27 & 2 & 40 & 38 & 2 \\
\hline Total & 32 & 55 & 100 & 37 & 69 & 100 \\
\hline
\end{tabular}


Table 4: Parameter estimates use of the Solidarity Fund conditional on eligibility; logit specification

\begin{tabular}{l|c|c}
\hline & \multicolumn{1}{|c|}{ Males } & Females \\
\hline Potential withdrawals 2 & $-0.04(0.9)$ & $-0.16(2.8)^{* *}$ \\
Potential withdrawals 3 & $-0.57(10.7)^{* *}$ & $-0.86(11.6)^{* *}$ \\
Potential withdrawals 4 & $-1.26(10.7)^{* *}$ & $-1.42(9.1)^{* *}$ \\
\hline -Loglikelihood & $9,990.1$ & $5,345.1$ \\
$\mathrm{~N}$ & 15,793 & 9,619 \\
\hline
\end{tabular}

Note: All estimates contain a constant and dummy variables for educational attainment (3), industry (15), region (14), birth year cohort (4) and year of entrance (2); absolute t-statistics in parentheses; a ** $(*)$ indicates significance at a $95 \%(90 \%)$ level. 
Table 5: Parameter estimates job finding rates - males

\begin{tabular}{|c|c|c|c|}
\hline & $\begin{array}{l}\text { Not entitled } \\
\quad \text { to SF }\end{array}$ & $\begin{array}{l}\text { Opting } \\
\text { for SF }\end{array}$ & $\begin{array}{l}\text { Not opting } \\
\text { for SF }\end{array}$ \\
\hline Potential withdrawals 2 & $0.03(1.1)$ & $0.29(7.5)^{* *}$ & $0.05(1.2)$ \\
\hline Potential withdrawals 3 & $0.01(0.3)$ & $0.37(6.7)^{* *}$ & $0.01(0.2)$ \\
\hline $\begin{array}{l}\text { Potential withdrawals } 4 \\
\text { Duration dependence }\end{array}$ & $0.08(0.5)$ & $0.07(0.5)$ & $0.15(1.6)$ \\
\hline Month 2 & $-0.13(6.4)^{* *}$ & $0.55(7.9)^{* *}$ & $-0.08(1.8)^{*}$ \\
\hline Month 3 & $-0.15(6.3)^{* *}$ & $0.85(12.6)^{* *}$ & $0.00(0.0)$ \\
\hline Month 4 & $-0.11(3.8)^{* *}$ & $1.05(15.4)^{* *}$ & $0.03(0.4)$ \\
\hline Month 5 & $-0.25(7.2)^{* *}$ & $1.29(18.9)^{* *}$ & $-0.08(1.1)$ \\
\hline Month 6 & $-0.24(5.9)^{* *}$ & $1.31(18.1)^{* *}$ & $-0.13(1.4)$ \\
\hline Month 7 & $-0.29(6.3)^{* *}$ & $1.28(16.6)^{* *}$ & $-0.16(1.5)$ \\
\hline Month 8 & $-0.39(7.2)^{* *}$ & $1.31(15.7)^{* *}$ & $-0.27(2.3)^{* *}$ \\
\hline Month 9 & $-0.42(7.0)^{* *}$ & $1.22(13.4)^{* *}$ & $-0.31(2.3)^{* *}$ \\
\hline Month 10 & $-0.48(7.3)^{* *}$ & $1.12(11.3)^{* *}$ & $-0.27(1.8)^{*}$ \\
\hline Month 11 & $-0.49(6.8)^{* *}$ & $1.11(10.5)^{* *}$ & $-0.31(1.9)^{*}$ \\
\hline Month 12 & $-0.55(7.0)^{* *}$ & $1.08(9.4)^{* *}$ & $-0.40(2.3)^{* *}$ \\
\hline $\begin{array}{l}\text { Month } \geq 13 \\
\text { Unobserved heterogeneity }\end{array}$ & $-0.62(7.7)^{* *}$ & $0.99(8.5)^{* *}$ & $-0.53(3.0)^{* *}$ \\
\hline$\alpha$ & $1.09(9.5)^{* *}$ & $0.97(5.1)^{* *}$ & $1.00(5.5)^{* *}$ \\
\hline$u^{b}$ & $-1.74(27.7)^{* *}$ & $-1.91(17.4)^{* *}$ & $-1.81(12.9)^{* *}$ \\
\hline -Loglikelihood & $87,894.5$ & $24,127.9$ & $17,851.4$ \\
\hline $\mathrm{N}$ & 33909 & 8708 & 7085 \\
\hline Test on selectivity & & \\
\hline$\alpha$ & - & \multicolumn{2}{|c|}{$0.96(8.1)^{* *}$} \\
\hline$u^{b}$ & - & \multicolumn{2}{|c|}{$-1.88(22.6)^{* *}$} \\
\hline -Loglikelihood & - & \multicolumn{2}{|c|}{$41,979.5$} \\
\hline LR test & - & \multicolumn{2}{|c|}{0.4} \\
\hline
\end{tabular}

Note: All estimates contain a constant and dummy variables for educational attainment (3), industry (15), region (14), birth year cohort (4) and year of entrance (2); absolute t-statistics in parentheses; a ** $\left(^{*}\right)$ indicates significance at a $95 \%(90 \%)$ level. 


\section{Table 6: Parameter estimates job finding rates - females}

\begin{tabular}{|c|c|c|c|}
\hline & $\begin{array}{l}\text { Not entitled } \\
\text { to SF }\end{array}$ & $\begin{array}{l}\text { Opting } \\
\text { for SF }\end{array}$ & $\begin{array}{l}\text { Not opting } \\
\text { for SF }\end{array}$ \\
\hline Potential withdrawals 2 & $-0.04(1.3)$ & $0.33(6.6)^{* *}$ & $0.19(3.0)^{* *}$ \\
\hline Potential withdrawals 3 & $-0.05(1.1)$ & $0.38(5.0)^{* *}$ & $0.22(2.8)^{* *}$ \\
\hline Potential withdrawals 4 & $0.04(0.3)$ & $0.43(2.0)^{* *}$ & $0.12(0.8)$ \\
\hline \multicolumn{4}{|l|}{ Duration dependence } \\
\hline Month 2 & $-0.23(5.8)^{* *}$ & $0.52(4.7)^{* *}$ & $-0.23(3.0)^{* *}$ \\
\hline Month 3 & $-0.02(0.4)$ & $0.89(8.4)^{* *}$ & $-0.09(1.2)$ \\
\hline Month 4 & $-0.03(0.6)$ & $1.12(10.8)^{* *}$ & $-0.14(1.6)^{*}$ \\
\hline Month 5 & $-0.09(1.6)$ & $1.49(14.6)^{* *}$ & $-0.22(2.4)^{* *}$ \\
\hline Month 6 & $-0.02(0.4)$ & $1.57(15.1)^{* *}$ & $-0.45(4.3)^{* *}$ \\
\hline Month 7 & $-0.22(3.1)^{* *}$ & $1.45(13.2)^{* *}$ & $-0.32(3.0)^{*}$ \\
\hline Month 8 & $-0.28(3.6)^{* *}$ & $1.57(13.9)^{* *}$ & $-0.55(4.4)^{* *}$ \\
\hline Month 9 & $-0.27(3.2)^{* *}$ & $1.56(13.0)^{* *}$ & $-0.58(4.4)^{* *}$ \\
\hline Month 10 & $-0.42(4.5)^{* *}$ & $1.49(11.8)^{* *}$ & $-0.49(3.0)^{* *}$ \\
\hline Month 11 & $-0.31(3.1)^{* *}$ & $1.37(10.1)^{* *}$ & $-0.64(4.3)^{* *}$ \\
\hline Month 12 & $-0.36(3.4)^{* *}$ & $1.40(9.8)^{* *}$ & $-0.84(4.8)^{* *}$ \\
\hline Month $\geq 13$ & $-0.43(3.9)^{* *}$ & $1.32(9.3)^{* *}$ & $-0.99(8.2)^{* *}$ \\
\hline \multicolumn{4}{|l|}{ Unobserved heterogeneity } \\
\hline$\alpha$ & $0.36(1.8)^{*}$ & $0.32(1.6)$ & $1.95(13.0)^{* *}$ \\
\hline$u^{b}$ & $-2.12(24.2)^{* *}$ & $-2.04(17.0)^{* *}$ & $-\infty$ \\
\hline -Loglikelihood & $42,070.2$ & $17,012.9$ & $7,649.8$ \\
\hline $\mathrm{N}$ & 16657 & 6602 & 3017 \\
\hline \multicolumn{4}{|l|}{ Test on selectivity } \\
\hline$\alpha$ & - & \multicolumn{2}{|c|}{$0.54(3.2)^{* *}$} \\
\hline$u^{b}$ & - & \multicolumn{2}{|c|}{$-2.04(17.3)^{* *}$} \\
\hline -Loglikelihood & - & \multicolumn{2}{|c|}{$24,666.1$} \\
\hline LR test & - & \multicolumn{2}{|c|}{$6.8^{* *}$} \\
\hline
\end{tabular}

Note: All estimates contain a constant and dummy variables for educational attainment (3), industry (15), region (14), birth year cohort (4) and year of entrance (2); absolute t-statistics in parentheses; a ${ }^{* *}(*)$ indicates significance at a $95 \%(90 \%)$ level. 
Table 7: Parameter estimates job finding rates; workers entitled to use SF sensitivity analysis

\begin{tabular}{l|cc|cc}
\hline \multirow{2}{*}{} & \multicolumn{3}{|c|}{ Males } & \multicolumn{2}{c}{ Females } \\
& Opting & Not opting & Opting & Not opting \\
& for SF & for SF & for SF & for SF \\
\hline log AB & $0.29(9.2)^{* *}$ & $-0.01(0.4)$ & $0.37(8.9)^{* *}$ & $0.14(3.3)^{* *}$ \\
$\alpha$ & $0.82(5.4)^{* *}$ & $1.02(5.8)^{* *}$ & $0.26(1.3)$ & $2.10(10.7)^{* *}$ \\
$u^{b}$ & $-1.89(19.9)^{* *}$ & $-1.83(13.1)^{* *}$ & $-1.98(17.0)^{* *}$ & $-\infty$ \\
-Loglikelihood & $24,119.6$ & $17,853.1$ & $16,992.9$ & $7,650.2$ \\
\hline N & 8708 & 7085 & 6602 & 3017 \\
\hline LR test selectivity & \multicolumn{3}{|c|}{0.6} & \multicolumn{3}{c}{$4.8^{* *}$} \\
\hline
\end{tabular}

Note: All estimates contain a constant and dummy variables for educational attainment (3), industry (15), region (14), birth year cohort (4) and year of entrance (2); absolute t-statistics in parentheses; a ** $(*)$ indicates significance at a $95 \%(90 \%)$ level. 